\title{
Doxorubicin-Induced Cardiac Toxicity Is Mediated by Lowering of Peroxisome Proliferator-Activated Receptor $\delta$ Expression in Rats
}

\author{
Zhih-Cherng Chen, ${ }^{1,2,3}$ Li-Jen Chen, ${ }^{4}$ and Juei-Tang Cheng ${ }^{2,4,5}$ \\ ${ }^{1}$ Department of Cardiology, Chi-Mei Medical Center, Yong Kang City, Tainan County 73101, Taiwan \\ ${ }^{2}$ Department of Medical Research, Chi-Mei Medical Center, Yong Kang City, Tainan County 73101, Taiwan \\ ${ }^{3}$ Department of Pharmacy, Chia Nan University of Pharmacy \& Science, Jean-Tae City, Tainan County 71701, Taiwan \\ ${ }^{4}$ Institute of Basic Medical Sciences, College of Medicine, National Cheng Kung University, Tainan City 70101, Taiwan \\ ${ }^{5}$ Institute of Medical Sciences, Chang Jung Christian University, Quei-Ren, Tainan City 71101, Taiwan
}

Correspondence should be addressed to Juei-Tang Cheng; jtcheng@mail.ncku.edu.tw

Received 21 September 2012; Revised 29 December 2012; Accepted 29 January 2013

Academic Editor: Richard P. Phipps

Copyright (C) 2013 Zhih-Cherng Chen et al. This is an open access article distributed under the Creative Commons Attribution License, which permits unrestricted use, distribution, and reproduction in any medium, provided the original work is properly cited.

\begin{abstract}
The present study investigates the changes of peroxisome proliferator-activated receptors $\delta$ (PPAR $\delta$ ) expression and troponin phosphorylation in heart of rats which were treated with doxorubicin (DOX). Wistar rats which were treated with DOX according to a previous method. The protein levels of PPAR $\delta$ and troponin phosphorylation were measured using Western blot. The PPAR $\delta$ expression in heart was markedly reduced in DOX-treated rats showing a marked decrease in cardiac $\mathrm{dP} / \mathrm{dT}$ and cardiac output. Also, cardiac troponin phosphorylation was lowered in DOX-treated rats. Meanwhile, combined treatment with the agonist of PPAR $\delta$ (GW0742) reversed the decrease of cardiac $\mathrm{dP} / \mathrm{dT}$ and cardiac output in DOX-treated rats. Then, primary cultured cardiomyocytes from neonatal rats were used to measure the changes of calcium concentration in cells. In addition to both decrease of PPAR $\delta$ expression and troponin phosphorylation in neonatal cardiomyocytes by DOX, a marked decrease of calcium concentration was also observed. Our results suggest the mediation of cardiac PPAR $\delta$ in DOX-induced cardiotoxicity in rats. Thus, activation of PPAR $\delta$ may restore the expression of $\mathrm{p}-\mathrm{TnI}$ and the cardiac performance in DOX-induced cardio toxicity in rats.
\end{abstract}

\section{Introduction}

Doxorubicin (DOX) is a widely used chemotherapeutic agent in the treatment of tumors with a major side effect of cardiac toxicity $[1,2]$, which has not been effectively prevented by cardioprotective drugs $[3,4]$. Thus, its clinical use is limited due to a cumulative dose-dependent cardiotoxicity including the electrocardiographic changes, arrhythmias, irreversible degenerative cardiomyopathy, and congestive heart failure [5-8]. The recent report showed that approximately $10 \%$ of patients treated with DOX or its derivatives will develop cardiac complications up to 10 years after cessation of chemotherapy [9]. Actually, the mechanism for cardiac toxicity caused by DOX or its metabolites is still not clear. Hypotheses regarding the cardiac toxicity of DOX include perturbation of calcium homeostasis, formation of iron complexes, and generation of radical oxygen species, mitochondrial dysfunction, and damage to cell membranes $[10,11]$.

PPARs are ligand-activated transcriptional factors that regulate expression of genes involved in lipid metabolism and inflammation [12]. Three subtypes of PPARs, PPAR $\alpha, \operatorname{PPAR} \gamma$, and PPAR $\delta$, modulate the expressions of many genes and exert various bioactivities [12]. PPAR $\alpha$ is relatively abundant in tissues with a high oxidative capacity, such as liver and heart. PPAR $\gamma$ expression is confined to a limited number of tissues, primarily adipose tissue $[12,13]$. The ubiquitously expressed PPAR $\delta$ enhances the lipid catabolism in adipose tissue and muscle [12]. PPAR $\delta$-dependent maintenance of inotropic function and metabolic effects is crucial for cardiomyocytes [14-16]. Deletion of cardiac PPAR $\delta$, which is 
accompanied by decreased contraction, increased left ventricular end-diastolic pressure, and lowered cardiac output, leads to decreased contraction and increased incidence of cardiac failure [14].

Our previous study showed that cardiomyopathy in type1 like diabetic rats is associated with a marked decrease in cardiac PPAR $\delta$ expression [17]. It seems possible that cardiac $\operatorname{PPAR} \delta$ expression is involved in the cardiac toxicity of DOX. Thus, in the present study, we used Wistar rats and primary neonatal rat cardiomyocytes to investigate the role of PPAR $\delta$ in DOX-induced heart failure both in vivo and in vitro.

\section{Materials and Methods}

2.1. Materials. Doxorubicin from Sigma-Aldrich (St Louis, MO, USA) and GW0742 from Santa Cruz Biotechnology (Santa Cruz, CA, USA) were used. The fluorescent probe, Fura-2, was obtained from Molecular Probes (Eugene, OR, USA). Antibodies to PPAR $\delta$ and actin were purchased from Abcam (Cambridge, MA, USA). Antibodies to cardiac TnI and phospho-TnI (Ser 23/24) were purchased from Cell Signaling Technology (Beverly, MA, USA).

2.2. Animal Model. All animal procedures were performed according to the Guide for the Care and Use of Laboratory Animals published by the US National Institutes of Health (NIH Publication No. 85-23, revised 1996), as well as the guidelines of the Animal Welfare Act. The male Wistar rats, weighing from 200 to $250 \mathrm{~g}$, were obtained from the Animal Center of National Cheng Kung University Medical College. Heart failure was induced by intraperitoneal injection of $15 \mathrm{mg} / \mathrm{kg}$ DOX according to previous report [8]. It is well established that bolus injection of DOX $(15 \mathrm{mg} / \mathrm{kg})$ is enough to cause acute cardiomyopathy in rodent [18]. Otherwise, GW0742, a PPAR $\delta$-specific activator [19], was dissolved in Dulbecco's modified Eagle's medium/dimethyl sulphoxide (DMSO) 6\% (Gibco) and injected subcutaneously once a day at $1 \mathrm{mg} / \mathrm{kg}$ in DOX-treated rats. Another group of DOX-treated rats receiving same treatment with vehicle at same volume was used for comparison. Meanwhile, the agematched normal rats receiving same treatments were taken as control. Then, under anesthesia with an inhalation of isoflurane (5\%), they were cannulated in the right femoral artery with polyethylene catheters (PE-50). Mean arterial pressure (MAP) and heart rate (HR) were recorded using a polygraph (MP35, BIOPAC, Goleta, CA, USA). The rat's trachea was intubated for artificial ventilation (Small Animal Ventilator Model 683, Harvard Apparatus, Holliston, M) at 50 breaths/min with a tidal volume of $8 \mathrm{~mL} / \mathrm{kg}$ and a positive end-expiratory pressure of $5 \mathrm{~cm} \mathrm{H}_{2} \mathrm{O}$. After incision into the rat's chest at the third intercostals space to expose the heart, a small section ( $1 \mathrm{~cm}$ long) of the ascending aorta was freed from the connective tissue. A Transonic Flow Probe (2.5PSB923, Transonic System Inc., Ithaca, NY, USA) was implanted around the root of the ascending aorta and connected to a Transonic transit-time blood flowmeter (T403, Transonic System Inc.). The cardiac output (CO) was calculated from the aortic blood flow, and the stroke volume (SV) was expressed as $\mathrm{CO}$ divided by HR. After the determination, the hearts were isolated from the anesthetized rats, rinsed with ice-cold phosphate-buffered saline (PBS), gently blotted, and weighed for western blotting analysis. All animal procedures were performed according to the Guide for the Care and Use of Laboratory Animals published by the US National Institutes of Health (NIH Publication No. 85-23, revised 1996), as well as the guidelines of the Animal Welfare Act.

2.3. Cell Culture and Treatment. Primary cultures of neonatal rat cardiomyocytes were prepared by a previous method [20] with modification. Briefly, under anesthesia with an inhalation of isoflurane (5\%), the heart tissue from a 1 to 2 day-old Wistar rat was cut into $1-$ to $2-\mathrm{mm}$ pieces and predigested with trypsin to remove the red blood cells. The heart tissue was then digested with $0.25 \%$ trypsin and $0.05 \%$ collagenase. The dissociated cells were placed in uncoated $10 \mathrm{~cm}$ dishes and incubated at $37^{\circ} \mathrm{C}$ in a $5 \% \mathrm{CO}_{2}$ incubator for at least $1 \mathrm{~h}$ to remove the nonmyocyte cells. This procedure caused most of the fibroblasts to attach to the dishes, while most of the cardiomyocytes remained unattached. The population of cells enriched in cardiomyocytes was then collected and counted. The cells were cultured in DMEM (GIBCO BRL, Gaithersburg, MD, USA) with $1 \mathrm{mmol} / \mathrm{L}$ pyruvate, $10 \%$ fetal bovine serum (FBS), 100 units/mL penicillin, and 100 units/mL streptomycin. On the second day after plating, the medium was replaced. Three days after plating, the cells were exposed to hyperglycemic conditions as described in detail later. Animal handling and disposal were performed in accordance with NIH guidelines.

The DOX-treated cardiomyocytes were generated by treating the cells with $10^{-9} \sim 10^{-6} \mathrm{~mol} / \mathrm{L}$ DOX for $24 \mathrm{~h} \mathrm{[21].}$ Then, cells were collected and subjected for Western blotting analysis. The treatment with GW0742 (PPAR $\delta$ agonist) was performed at $10^{-6} \mathrm{~mol} / \mathrm{L}$ for 1 hour before the addition of DOX as described previously $[15,22]$.

2.4. Western Blotting Analysis. Protein was extracted from tissue homogenates and cell lysates using ice-cold RIPA buffer supplemented with phosphatase and protease inhibitors ( $50 \mathrm{mmol} / \mathrm{L}$ sodium vanadate, $0.5 \mathrm{mM}$ phenylmethylsulphonyl fluoride, $2 \mathrm{mg} / \mathrm{mL}$ aprotinin, and $0.5 \mathrm{mg} / \mathrm{mL}$ leupeptin). Protein concentrations were determined with the BioRad protein assay (Bio-Rad Laboratories, Inc., Hercules, CA, USA). Total proteins $(30 \mu \mathrm{g})$ were separated by SDS/polyacrylamide gel electrophoresis ( $10 \%$ acrylamide gel) using the Bio-Rad Mini-Protein II system. Protein was transferred to expanded polyvinylidene difluoride membranes (Pierce, Rockford, IL, USA) with a Bio-Rad TransBlot system. After transfer, the membranes were washed with PBS and blocked for $1 \mathrm{~h}$ at room temperature with 5\% (w/v) skimmed milk powder in PBS. The manufacturer's instructions were followed for the primary antibody reactions. Blots were incubated overnight at $4^{\circ} \mathrm{C}$ with an immunoglobulin-G polyclonal rabbit anti-mouse antibody (Affinity BioReagents, Inc., Golden, CO, USA) (1:500) in 5\% (w/v) skimmed milk powder dissolved in PBS/Tween 20 (0.5\% by volume) to bind the PPAR $\delta$ in the heart specimens. The blot was incubated 
with goat polyclonal antibody $(1: 1000)$ to bind the actin serving as internal control. After the removal of primary antibody, the blots were extensively washed with PBS/Tween 20. The blots were then incubated for $2 \mathrm{~h}$ at room temperature with the appropriate peroxidase-conjugated secondary antibody diluted in $5 \%(\mathrm{w} / \mathrm{v})$ of skimmed milk powder and dissolved in PBS/Tween 20. The blots were developed by autoradiography using the ECL-western blotting system (Amersham International, Buckinghamshire, UK). The immune blot of PPAR $\delta$ $(49 \mathrm{kDa})$, actin $(43 \mathrm{kDa})$, cardiac troponin $(28 \mathrm{kDa})$, and phospho-troponin were quantified with a laser densitometer.

\subsection{Measurement of Intracellular Calcium Concentration.} The changes in intracellular calcium were detected using the fluorescent probe Fura-2 [23]. The neonatal cardiomyocytes were placed in buffered physiological saline solution containing $140 \mathrm{mM} \mathrm{NaCl}, 5.9 \mathrm{mM} \mathrm{KCI}, 1.2 \mathrm{mM} \mathrm{CaCl}_{2}, 1.4 \mathrm{mM}$ $\mathrm{MgCl}_{2}, 11.5 \mathrm{mM}$ glucose, $1.8 \mathrm{mM} \mathrm{Na} \mathrm{NPO}_{4}$, and $10 \mathrm{mM}$ Hepes-Tris, to which was added $5 \mu \mathrm{M}$ fura-2, and incubated for $1 \mathrm{~h}$ in humidified $5 \% \mathrm{CO}_{2}$ and $95 \%$ air at $37^{\circ} \mathrm{C}$. The cells were washed and incubated an additional $30 \mathrm{~min}$ in PSS. The cells were inserted into a thermostated $\left(37^{\circ} \mathrm{C}\right)$ cuvette containing $2 \mathrm{~mL}$ of calcium-free PSS. The fluorescence was continuously recorded using a fluorescence spectrofluorometer (Hitachi F-2000, Tokyo, Japan). Values of $\left[\mathrm{Ca}^{2+}\right] i$ were calculated from the ratio $R=F 340 / F 380$ by the formula: $\left[\mathrm{Ca}^{2+}\right] i=\mathrm{Kd} B\left(R-R_{\min }\right) /\left(R_{\max }-R\right)$, where $\mathrm{Kd}$ is $225 \mathrm{nM}, F$ is fluorescence, and $B$ is the ratio of the fluorescence of the free dye to that of the $\mathrm{Ca}^{2+}$-bound dye measured at $380 \mathrm{~nm}$. Background autofluorescence was measured in unloaded cells and subtracted from all measurements.

2.6. Catheterization for Hemodynamic dP/dt Measurement. Temporary pacing leads were used for short-term study and were placed in the right atrium and RV apex. A venogram imaged in 2 different angulations (left anterior oblique $30^{\circ}$ and anteroposterior) was obtained to determine the anatomy of the coronary sinus venous system. An LV pacing electrode (IX-214; iWorx Systems, Inc., Dover, NH, USA) was placed either in the free wall region via the lateral or posterior vein or in the anterior region via the great cardiac vein. After femoral artery and venous puncture using the Seldinger technique [24], pressure transducer catheters were inserted into the heart to provide the RV, aortic, and LV pressures. Pressure catheters and pacing leads were connected to an external pacing computer (iWorx Systems, Inc., Dover, NH, USA) to execute the pacing protocol and to acquire hemodynamic signals.

2.7. Statistical Analysis. Data are expressed as the mean \pm SEM for the number $(n)$ of animals in one group as indicated. Statistical analysis was carried out using repeated measures analysis of variance (ANOVA) and Newman-Keuls post-hoc analysis. Bonferroni's correction was applied to the data, which were obtained from relatively small groups. A $P$ value of 0.05 or less was considered significant.

\section{Results}

3.1. Effects of GW0742 on PPAR Expression and Cardiac Troponin I Phosphorylation in DOX-Treated Rats. The levels of PPAR $\delta$ protein expression and cardiac troponin I phosphorylation were significantly reduced in the heart of DOX-treated rats, compared with the control rats (Figure 1). Moreover, the decrease in expression of PPAR $\delta$ or cardiac Troponin I phosphorylation was markedly reversed by GW0742 in DOX-treated rats (Figure 1).

3.2. Improvement of Cardiac Function in DOX-Treated Rats by GW0742. The values of cardiac output in addition to maxdP/dt and mindP/dt were significantly $(P<0.001)$ reduced in DOX-treated rats as compared with the control rats. Also, the decrease in cardiac output or maxdP/dt and mindP/dt was markedly reversed in DOX-treated rats after a 3-day treatment with GW0742 (1 mg/kg), as shown in Figures 2 (a) and 2(b).

3.3. Effects of Doxorubicin on the Reduction of PPAR Expression and Cardiac Troponin I Phosphorylation in Neonatal Rat Cardiomyocytes. We used primary neonatal rat cardiomyocytes to investigate the effects of DOX on expression of PPAR $\delta$ and cardiac Troponin I phosphorylation. After the incubation with $10^{-9} \sim 10^{-6} \mathrm{~mol} / \mathrm{L}$ DOX for $24 \mathrm{~h}$, the cells were harvested to compare the expression of PPAR $\delta$ and the level of cardiac Troponin I phosphorylation in cells. The expression of PPAR $\delta$ protein and the level of cardiac troponin I phosphorylation in neonatal rat cardiomyocytes were significantly reduced by DOX treatment in a concentrationrelated manner (Figure 3). Then, the most effective dose $\left(10^{-6} \mathrm{~mol} / \mathrm{L}\right)$ of DOX was used in the fallowing studies.

\subsection{Effects of GW0742 on PPARS Expression and Cardiac} Troponin I Phosphorylation in DOX-Treated Neonatal Rat Cardiomyocytes. The decrease in expression of PPAR $\delta$ protein or cardiac Troponin I phosphorylation was restored by treatment with GW0742 in DOX-treated cells, respectively (Figure 4).

3.5. Effects of GW0742 on the Intracellular Concentration of Calcium in DOX-Treated Neonatal Rat Cardiomyocytes. The fluorescent probe, fura2-AM, was used to detect the intracellular calcium concentration in DOX-treated neonatal rat cardiomyocytes. As compared with control, GW0742 restored the intracellular calcium concentration in DOXtreated cardiomyocytes (Figure 5).

\section{Discussion}

The present study found that gene expression of PPAR $\delta$ is reduced in rats with doxorubicin-(DOX-) induced cardiac toxicity. Also, activation of PPAR $\delta$ may improve the cardiac performance damaged by DOX. Thus, we suggest the first report regarding the important role of PPAR $\delta$ in DOXinduced cardiac toxicity. 

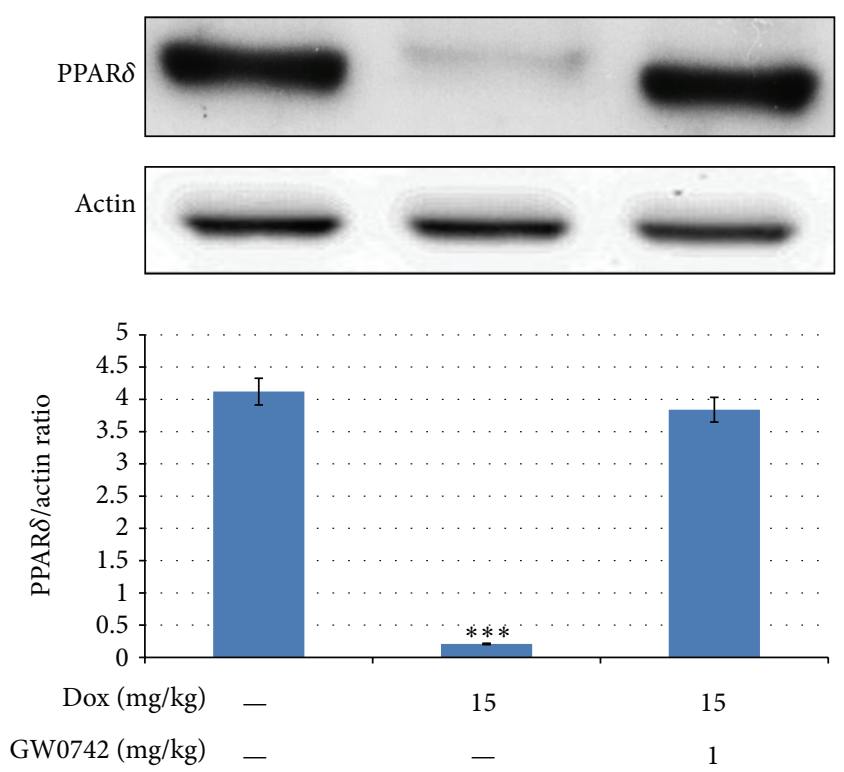

(a)
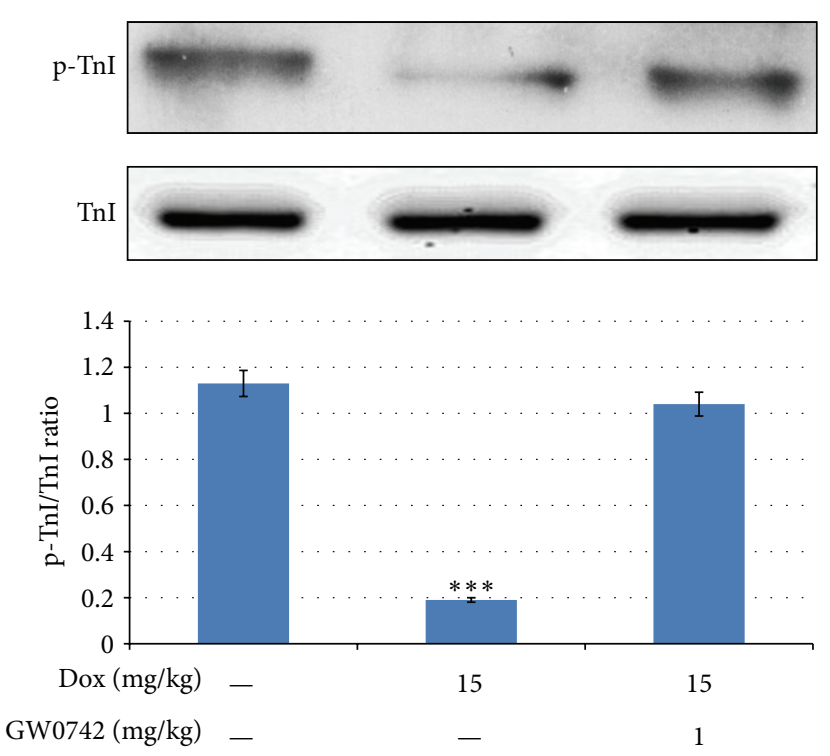

(b)

FIgURE 1: PPAR $\delta$ expression and TnI phosphorylation in hearts from DOX-treated rats, GW0742-added DOX-treated rats, or Wistar rats. Changes in cardiac PPAR $\delta$ protein expression (a) and the levels of cardiac TnI phosphorylation (b) were examined in age-matched Wistar rats (control rats), DOX-treated rats, and GW0742-added DOX-treated rats. All values are expressed as mean \pm SEM ( $n=6$ per group). ${ }^{*} P<0.05$ and ${ }^{* *} P<0.01$ as compared with Wistar rats.

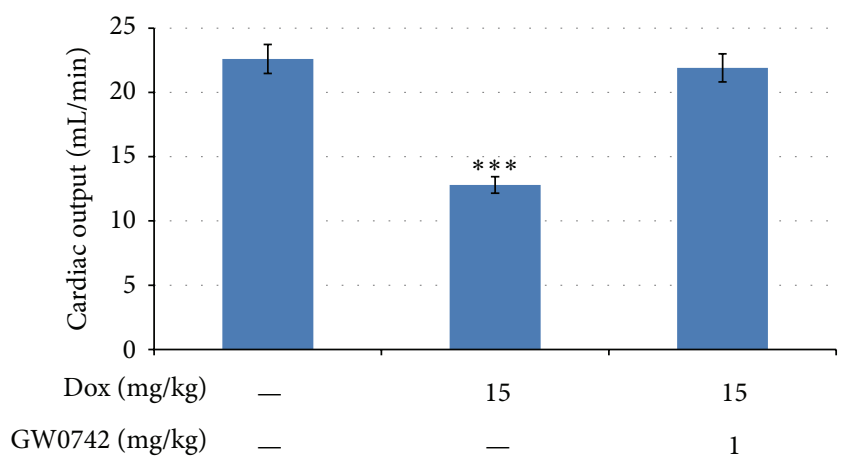

(a)

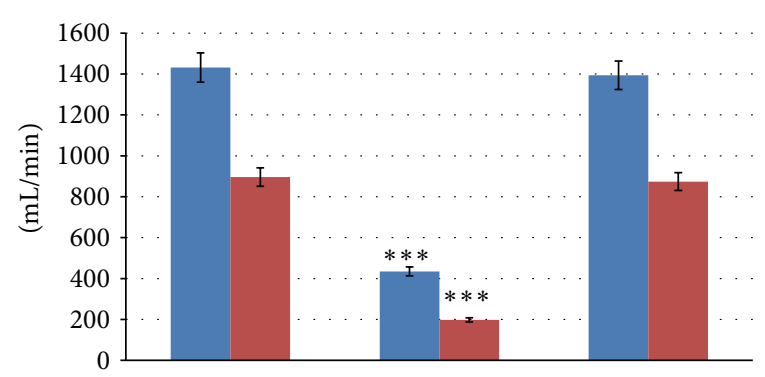

$\begin{array}{rr}\operatorname{Dox}(\mathrm{mg} / \mathrm{kg}) & - \\ \text { GW0742 (mg/kg) } & - \\ & \begin{array}{l}\mathrm{dP} / \mathrm{dt}+ \\ \mathrm{dP} / \mathrm{dt}-\end{array}\end{array}$
15

1

FIGURE 2: Effect of GW0742 on cardiac output and hemodynamic dP/dt in DOX-treated rats. Changes in cardiac output (a) and hemodynamic $\mathrm{dP} / \mathrm{dt}$ (b) in DOX-treated rats by a 3-day treatment of GW0742 (1 mg/kg, S.C). Data represent mean \pm SE of six experiments. ${ }^{* *} P<0.01$ as compared with control group.

According to a previous method [25], we established animal model showing DOX-induced cardiac toxicity that has been confirmed using the marked decrease in cardiac output and contraction $(\mathrm{dP} / \mathrm{dt})$ in addition to the lowering of cardiac Troponin I phosphorylation. Also, gene expression of cardiac PPAR $\delta$ is markedly reduced in this animal model. Mediation of PPAR $\delta$ in the lowering of cardiac performance induced by DOX can thus be considered. Actually, we found that a 3-day treatment with GW0742 at the dose sufficient to activate PPAR $\delta$ reverses the cardiac performance in DOXtreated rats. This is consistent with the view that cardiac PPAR $\delta$ is mediated in contraction of heart and decrease of PPAR $\delta$ is related to higher incidence of cardiac failure [14].

Then, we used the primary cultured cardiomyocytes from neonatal rats to investigate the potential mechanism(s). Although cardiac contraction was not determined, Troponin I phosphorylation was reduced in cardiomyocytes by DOX in a concentration-related manner. The reduced 

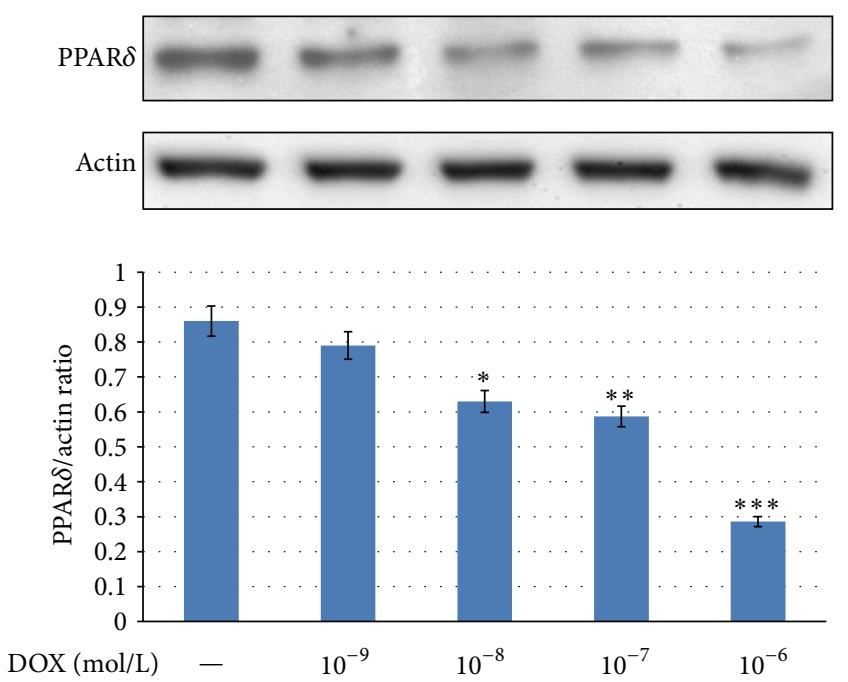

(a)
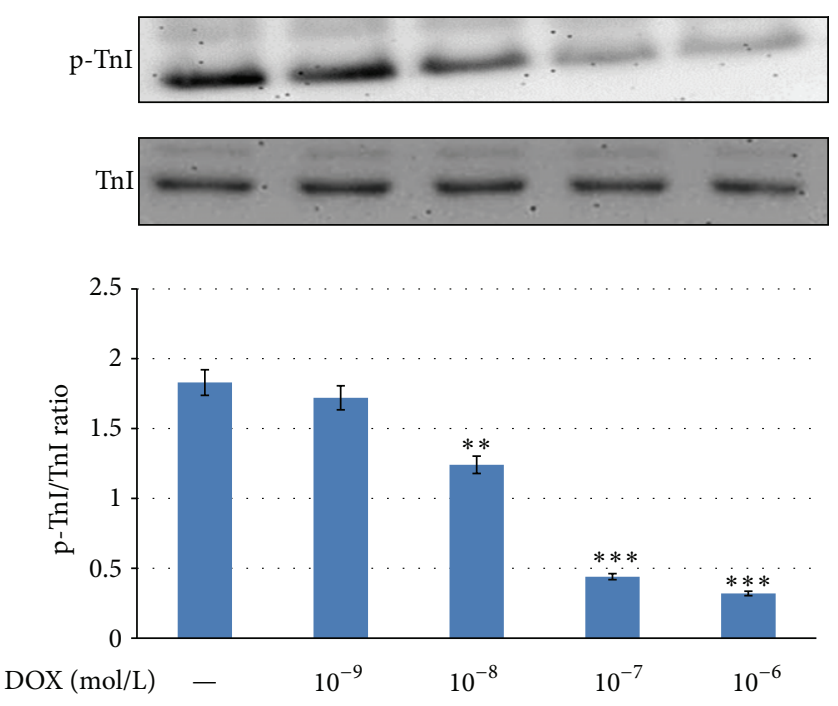

(b)

FIgURE 3: Effects of doxorubicin on PPAR $\delta$ expression and cardiac troponin I phosphorylation in neonatal rat cardiomyocytes. Cardiomyocytes from neonatal rats were cultured with $10^{-9} \sim 10^{-6} \mathrm{~mol} / \mathrm{L}$ doxorubicin for $24 \mathrm{~h}$. These cells were harvested to determine the expression of PPAR $\delta$ (a) and the level of troponin I phosphorylation (b) using Western blotting analysis. All values are presented as mean \pm $\operatorname{SEM}\left(n=6\right.$ per group). ${ }^{*} P<0.05,{ }^{* *} P<0.01$, and ${ }^{* * *} P<0.001$ as compared with control cells.
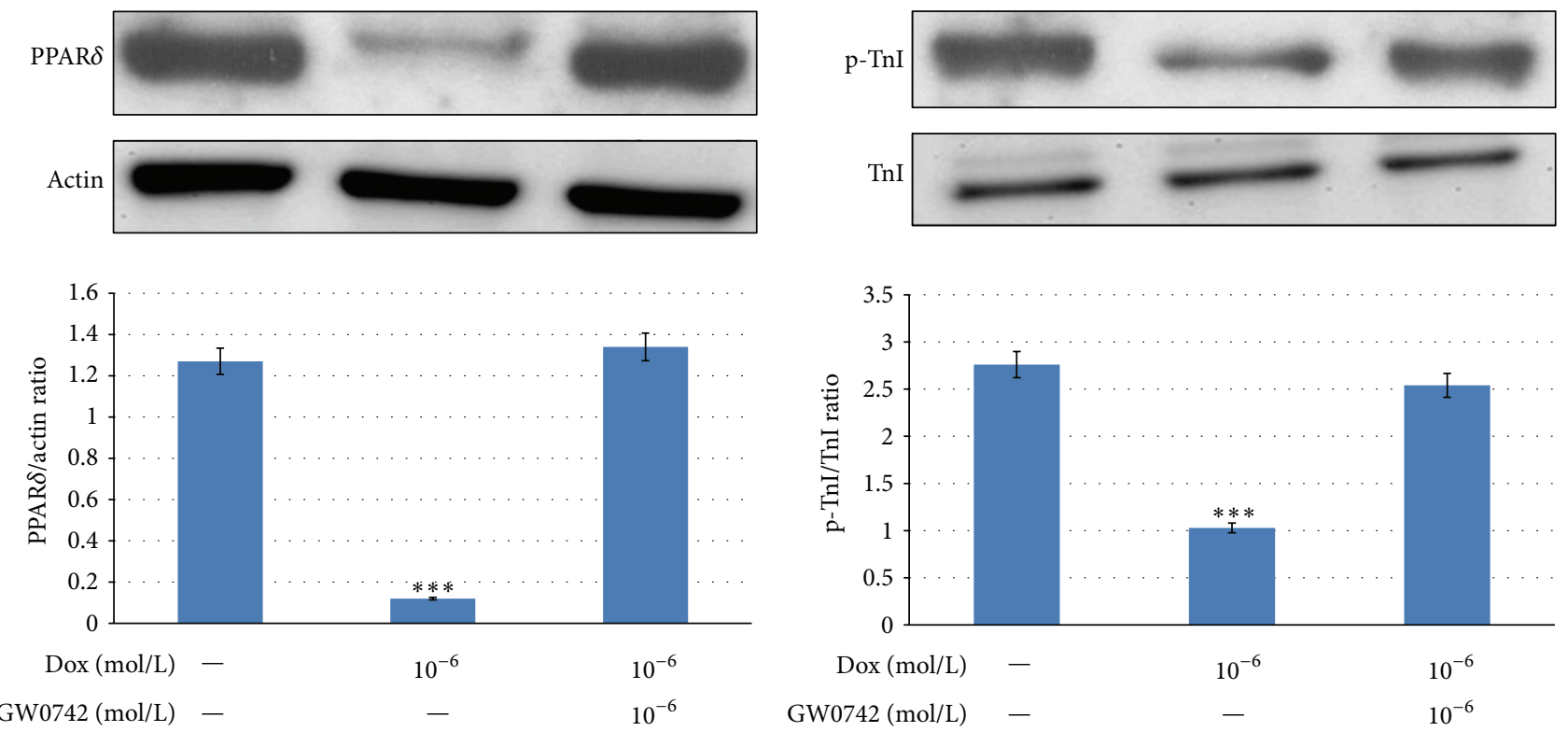

(a)

(b)

FiguRE 4: Effects of GW0742 on PPAR $\delta$ expression and cardiac troponin I phosphorylation in doxorubicin-treated neonatal rat cardiomyocytes. Changes of PPAR $\delta$ expression (a) and cardiac troponin I phosphorylation (b) in DOX-treated cells by GW0742. Cells were treated with $10^{-6} \mathrm{~mol} / \mathrm{L}$ GW0742 for 1 hour before the incubation with $10^{-6} \mathrm{~mol} / \mathrm{L}$ DOX. After $24 \mathrm{~h}$, they were harvested for measuring PPAR $\delta$ protein expression (a) and cardiac troponin I phosphorylation (b) by Western blot. All values are expressed as mean \pm SEM ( $n=6$ per group). ${ }^{*} P<0.05,{ }^{* *} P<0.01$, and ${ }^{* * *} P<0.001$ as compared with DOX-treated cells.

phosphorylation of Troponin I has been identified in the failing hearts of human studies [26]. Thus, the reduced Troponin I phosphorylation may indicate the contractile defects as shown in hearts induced by DOX. Moreover, PPAR $\delta$ expression is also parallel reduced by DOX in cardiomyocytes. DOX is one of the widely used agents for the treatment of cancer with a limitation in clinical utility due to the irreversible cardiac toxicity $[2,27,28]$. In the current work, we demonstrated that DOX impaired cardiac function with a decrease in cardiac PPAR $\delta$ expression both in vivo and in vitro. 


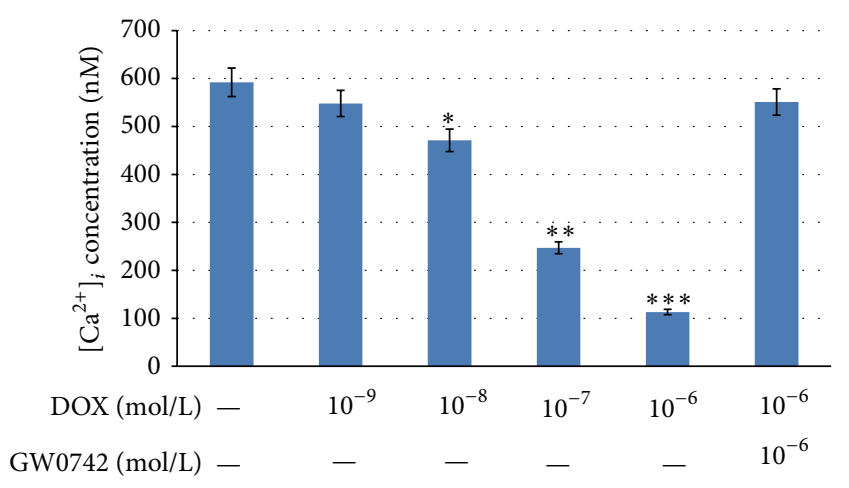

FIGURE 5: Effects of GW0742 on intracellular calcium release in DOX-treated neonatal rat cardiomyocytes. Changes in intracellular calcium concentration were detected by Fura- 2 using a fluorescence spectrofluorometer. Cells were treated with $10^{-6} \mathrm{~mol} / \mathrm{L}$ GW0742 for 1 hour before incubation with $10^{-6} \mathrm{~mol} / \mathrm{L}$ DOX and then used for measuring intracellular calcium concentration. All values are expressed as mean $\pm \operatorname{SEM}\left(n=6\right.$ per group). ${ }^{*} P<0.05,{ }^{* *} P<0.01$, and ${ }^{* * *} P<0.001$ as compared with DOX-treated cells.

The pathological mechanism of DOX-related late cardiotoxicity is multifactorial [29], but the prevalent hypothesis ascribes the dominant role to oxidative stress linked to redoxcycling of the drug $[30,31]$. The DOX redox-cycling is started from one-electron reduction with the formation of DOX radical $\left(\mathrm{DOX}^{*}\right)$ [32]. Previous study has shown that greater amount of reactive oxygen species (ROS) could reduce the $\operatorname{PPAR} \delta$ expression in the heart of rats under hyperglycemic condition [17]. In this work, we observed that PPAR $\delta$ expression is reduced by DOX in rats and cardiomyocytes and the redox unbalance induced by DOX may apply a possible mechanism of repression of PPAR $\delta$.

Both cardiac output and cardiac contraction identified using maxdP/dt and mindP/dt decreased in DOX-treated rats. A decrease in cardiac performance induced by DOX is characterized as described in previous reports [33]. Then, in the in vitro study, intracellular calcium concentration was also reduced in cardiomyocytes by DOX in a doserelated manner. This is consistent with the previous report $[34,35]$. Moreover, this change was reversed by GW0742 at concentration sufficient to activated PPAR $\delta$. The new view regarding the important role of PPAR $\delta$ in DOX-induced cardiac toxicity can thus be considered.

Previous studies have demonstrated that Troponin I phosphorylation most likely acts through an enhanced off rate during $\mathrm{Ca}^{2+}$ exchange with Troponin $\mathrm{C}$, leading to acceleration of relaxation and an increase in cardiac output [26, 36-39]. Recent studies also demonstrated that direct activation of PPAR $\delta$ by GW0742 may result in higher of TnI phosphorylation and cardiac performance. This action could be reversed after the treatment of calcium chelators [40-43]. A decrease in cardiac intracellular calcium may result in the lowering of Troponin I phosphorylation and this view has been identified in the present study. Furthermore, Troponin I phosphorylation was also reversed by GW0742 in the hearts of DOX-treated rats. Also, treat with GW0742 at effective dose as described previously $[44,45]$ was observed to improve cardiac performance in DOX-induced cardiotoxicity in rats. Taken together, it is suitable to speculate that the cardiotonic effect of GW0742 on DOX-induced cardiotoxicity seems related to an increase of $\mathrm{Ca}^{2+}$ concentration.

\section{Conclusions}

Cardiac PPAR $\delta$ plays an important role in DOX-induced cardiotoxicity in rats. Thus, activation of PPAR $\delta$ may restore the expression of $\mathrm{p}$-TnI and the cardiac performance in DOXinduced cardiotoxicity in rats.

\section{Conflict of Interests}

The authors have no conflict of interests about this study.

\section{Acknowledgments}

The authors appreciate the assistance of Miss P. L. Jou in immunoblotting analysis. The present study was supported in part by a Grant from the Chi-Mei Medical Center (CMFHR9953), Taiwan.

\section{References}

[1] S. Kumar, R. Marfatia, S. Tannenbaum, C. Yang, and E. Avelar, "Doxorubicin-induced cardiomyopathy 17 years after chemotherapy," Texas Heart Institute Journal, vol. 39, no. 3, pp. 424427, 2012.

[2] G. Takemura and H. Fujiwara, "Doxorubicin-induced cardiomyopathy from the cardiotoxic mechanisms to management," Progress in Cardiovascular Diseases, vol. 49, no. 5, pp. 330-352, 2007.

[3] M. I. Gharib and A. K. Burnett, "Chemotherapy-induced cardiotoxicity: current practice and prospects of prophylaxis," European Journal of Heart Failure, vol. 4, no. 3, pp. 235-242, 2002.

[4] J. Wojtacki, E. Lewicka-Nowak, and K. Lesniewski-Kmak, "Anthracycline-induced cardiotoxicity: clinical course, risk factors, pathogenesis, detection and prevention-review of the literature," Medical Science Monitor, vol. 6, no. 2, pp. 411-420, 2000.

[5] P. W. Fisher, F. Salloum, A. Das, H. Hyder, and R. C. Kukreja, "Phosphodiesterase-5 inhibition with sildenafil attenuates cardiomyocyte apoptosis and left ventricular dysfunction in a chronic model of doxorubicin cardiotoxicity," Circulation, vol. 111, no. 13, pp. 1601-1610, 2005.

[6] G. Fajardo, M. Zhao, J. Powers, and D. Bernstein, "Differential cardiotoxic/cardioprotective effects of $\beta$-adrenergic receptor subtypes in myocytes and fibroblasts in doxorubicin cardiomyopathy," Journal of Molecular and Cellular Cardiology, vol. 40, no. 3, pp. 375-383, 2006.

[7] F. Villani, E. Monti, and F. Piccinini, "Relationship between doxorubicin-induced ECG changes and myocardial alterations in rats," Tumori, vol. 72, no. 3, pp. 323-329, 1986.

[8] H. Alimoradi, A. Barzegar-Fallah, G. Hassanzadeh et al., "The cardioprotective effects of an antiemetic drug, tropisetron, on cardiomyopathy related to doxorubicin," Cardiovascular Toxicology, vol. 12, no. 4, pp. 318-325, 2012. 
[9] Y. Octavia, C. G. Tocchetti, K. L. Gabrielson, S. Janssens, H. J. Crijns, and A. L. Moens, "Doxorubicin-induced cardiomyopathy: from molecular mechanisms to therapeutic strategies," Journal of Molecular and Cellular Cardiology, vol. 52, no. 6, pp. 1213-1225, 2012.

[10] A. Mordente, E. Meucci, G. E. Martorana, B. Giardina, and G. Minotti, "Human heart cytosolic reductases and anthracycline cardiotoxicity," IUBMB Life, vol. 52, no. 1-2, pp. 83-88, 2001.

[11] L. E. Olson, D. Bedja, S. J. Alvey, A. J. Cardounel, K. L. Gabrielson, and R. H. Reeves, "Protection from doxorubicin-induced cardiac toxicity in mice with a null allele of carbonyl reductase 1," Cancer Research, vol. 63, no. 20, pp. 6602-6606, 2003.

[12] Q. Yang and Y. Li, "Roles of PPARs on regulating myocardial energy and lipid homeostasis," Journal of Molecular Medicine, vol. 85, no. 7, pp. 697-706, 2007.

[13] I. Issemann and S. Green, "Activation of a member of the steroid hormone receptor superfamily by peroxisome proliferators," Nature, vol. 347, no. 6294, pp. 645-650, 1990.

[14] L. Cheng, G. Ding, Q. Qin et al., "Cardiomyocyte-restricted peroxisome proliferator-activated receptor- $\delta$ deletion perturbs myocardial fatty acid oxidation and leads to cardiomyopathy," Nature Medicine, vol. 10, no. 11, pp. 1245-1250, 2004.

[15] L. Cheng, G. Ding, Q. Qin et al., "Peroxisome proliferatoractivated receptor $\delta$ activates fatty acid oxidation in cultured neonatal and adult cardiomyocytes," Biochemical and Biophysical Research Communications, vol. 313, no. 2, pp. 277-286, 2004.

[16] G. D. Barish, V. A. Narkar, and R. M. Evans, "PPAR $\delta$ : a dagger in the heart of the metabolic syndrome," The Journal of Clinical Investigation, vol. 116, no. 3, pp. 590-597, 2006.

[17] B. C. Yu, C. K. Chang, H. Y. Ou, K. C. Cheng, and J. T. Cheng, "Decrease of peroxisome proliferator-activated receptor delta expression in cardiomyopathy of streptozotocin-induced diabetic rats," Cardiovascular Research, vol. 80, no. 1, pp. 78-87, 2008.

[18] M. Rahimi Balaei, M. Momeny, R. Babaeikelishomi, S. Ejtemaei Mehr, S. M. Tavangar, and A. R. Dehpour, "The modulatory effect of lithium on doxorubicin-induced cardiotoxicity in rat," European Journal of Pharmacology, vol. 641, no. 2-3, pp. 193-198, 2010.

[19] M. L. Sznaidman, C. D. Haffner, P. R. Maloney et al., "Novel selective small molecule agonists for peroxisome proliferatoractivated receptor $\delta($ PPAR $\delta)$-synthesis and biological activity," Bioorganic and Medicinal Chemistry Letters, vol. 13, no. 9, pp. 1517-1521, 2003.

[20] W. B. Kannel, M. Hjortland, and W. P. Castelli, "Role of diabetes in congestive heart failure: the Framingham study," American Journal of Cardiology, vol. 34, no. 1, pp. 29-34, 1974.

[21] T. Tokudome, T. Horio, M. Fukunaga et al., "Ventricular nonmyocytes inhibit doxorubicin-induced myocyte apoptosis: involvement of endogenous endothelin-1 as a paracrine factor," Endocrinology, vol. 145, no. 5, pp. 2458-2466, 2004.

[22] D. Kitz Krämer, L. Al-Khalili, S. Perrini et al., "Direct activation of glucose transport in primary human myotubes after activation of peroxisome proliferator-activated receptor $\delta$," Diabetes, vol. 54, no. 4, pp. 1157-1163, 2005.

[23] I. G. Poornima, P. Parikh, and R. P. Shannon, "Diabetic cardiomyopathy: the search for a unifying hypothesis," Circulation Research, vol. 98, no. 5, pp. 596-605, 2006.

[24] S. I. Seldinger, "Catheter replacement of the needle in percutaneous arteriography: a new technique," Acta Radiologica, vol. 49, no. 434, pp. 47-52, 2008.
[25] C. F. Brilhante Wolle, L. De Aguiar Zollmann, A. Etges, G. S. Vitalis, C. E. Leite, and M. M. Campos, "Effects of the antioxidant agent tempol on periapical lesions in rats with doxorubicin-induced cardiomyopathy," Journal of Endodontics, vol. 38, no. 2, pp. 191-195, 2012.

[26] A. E. Messer, A. M. Jacques, and S. B. Marston, “Troponin phosphorylation and regulatory function in human heart muscle: dephosphorylation of Ser23/24 on troponin I could account for the contractile defect in end-stage heart failure," Journal of Molecular and Cellular Cardiology, vol. 42, no. 1, pp. 247-259, 2007.

[27] S. E. Lipshultz, M. A. Grenier, S. D. Colan et al., "Doxorubicininduced cardiomyopathy," The New England Journal of Medicine, vol. 340, no. 8, pp. 653-655, 1999.

[28] A. Berdichevski, G. Meiry, F. Milman et al., “TVP1022 protects neonatal rat ventricular myocytes against doxorubicin-induced functional derangements," Journal of Pharmacology and Experimental Therapeutics, vol. 332, no. 2, pp. 413-420, 2010.

[29] G. Minotti, P. Menna, E. Salvatorelli, G. Cairo, and L. Gianni, "Anthracyclines: molecular advances and pharmacologie developments in antitumor activity and cardiotoxicity," Pharmacological Reviews, vol. 56, no. 2, pp. 185-229, 2004.

[30] M. F. Xu, P. L. Tang, Z. M. Qian, and M. Ashraf, "Effects by doxorubicin on the myocardium are mediated by oxygen free radicals," Life Sciences, vol. 68, no. 8, pp. 889-901, 2001.

[31] J. H. Doroshow, "Effect of anthracycline antibiotics on oxygen radical formation in rat heart," Cancer Research, vol. 43, no. 2, pp. 460-472, 1983.

[32] N. R. Bachur, S. L. Gordon, and M. V. Gee, "A general mechanism for microsomal activation of quinone anticancer agents to free radicals," Cancer Research, vol. 38, no. 6, pp. 1745$1750,1978$.

[33] J. H. Doroshow, "Doxorubicin-induced cardiac toxicity," The New England Journal of Medicine, vol. 324, no. 12, pp. 843-845, 1991.

[34] A. Aviles, N. Arevila, J. C. Diaz Maqueo, T. Gomez, R. Garcia, and M. J. Nambo, "Late cardiac toxicity of doxorubicin, epirubicin, and mitoxantrone therapy for Hodgkin's disease in adults," Leukemia and Lymphoma, vol. 11, no. 3-4, pp. 275-279, 1993.

[35] A. Avilés, N. Neri, M. J. Nambo, J. Huerta-Guzman, A. Talavera, and S. Cleto, "Late cardiac toxicity secondary to treatment in Hodgkin's disease. A study comparing doxorubicin, epirubicin and mitoxantrone in combined therapy," Leukemia and Lymphoma, vol. 46, no. 7, pp. 1023-1028, 2005.

[36] C. A. Tate, M. F. Hyek, and G. E. Taffet, "The role of calcium in the energetics of contracting skeletal muscle," Sports Medicine, vol. 12, no. 3, pp. 208-217, 1991.

[37] X. Liu, N. Takeda, and N. S. Dhalla, "Troponin I phosphorylation in heart homogenate from diabetic rat," Biochimica et Biophysica Acta, vol. 1316, no. 2, pp. 78-84, 1996.

[38] L. Li, J. Desantiago, G. Chu, E. G. Kranias, and D. M. Bers, "Phosphorylation of phospholamban and troponin I in $\beta$ adrenergic-induced acceleration of cardiac relaxation," American Journal of Physiology, vol. 278, no. 3, pp. H769-H779, 2000.

[39] Y. Pi, K. R. Kemnitz, D. Zhang, E. G. Kranias, and J. W. Walker, "Phosphorylation of troponin I controls cardiac twitch dynamics: evidence from phosphorylation site mutants expressed on a troponin I-null background in mice," Circulation Research, vol. 90, no. 6, pp. 649-656, 2002.

[40] M.-T. Chou, S.-H. Lo, K.-C. Cheng, Y.-X. Li, L.-J. Chen, and J.-T. Cheng, "Activation of $\beta$-adrenoceptors by dobutamine 
may induce a higher expression of peroxisome proliferatoractivated receptors $\delta(\operatorname{PPAR} \delta)$ in neonatal rat cardiomyocytes," The Scientific World Journal, vol. 2012, Article ID 248320, 8 pages, 2012.

[41] Z.-C. Chen, B.-C. Yu, L.-J. Chen, and J.-T. Cheng, "Increase of peroxisome proliferator-activated receptor delta (PPAR $\delta$ ) by digoxin to improve lipid metabolism in the heart of diabetic rats," Hormone and Metabolic Research, 2012.

[42] S. C. Fan, B. C. Yu, Z. C. Chen, L. J. Chen, H. H. Chung, and J. T. Cheng, "The decreased expression of peroxisome proliferatoractivated receptors (PPAR) is reversed by digoxin in the heart of diabetic rats," Hormone and Metabolic Research, vol. 42, no. 9, pp. 637-642, 2010.

[43] Z.-C. Chen, L.-J. Chen, and J.-T. Cheng, "Activation of peroxisome proliferator-activated receptor $\delta(\operatorname{PPAR} \delta)$ by agonist named gw0742 increases cardiac contractility but not heart beating in animal," British journal of pharmacology. In press.

[44] I. Paterniti, E. Mazzon, L. Riccardi et al., "Peroxisome proliferator-activated receptor $\beta / \delta$ agonist GW0742 ameliorates cerulein- and taurocholate-induced acute pancreatitis in mice," Surgery, vol. 152, no. 1, pp. 90-106, 2012.

[45] B. Faiola, J. G. Falls, R. A. Peterson et al., "PPAR alpha, more than PPAR delta, mediates the hepatic and skeletal muscle alterations induced by the PPAR agonist GW0742," Toxicological Sciences, vol. 105, no. 2, pp. 384-394, 2008. 


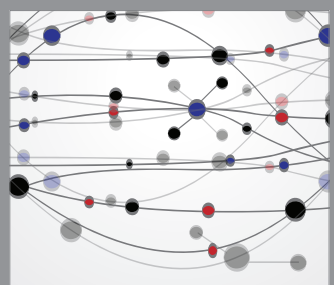

The Scientific World Journal
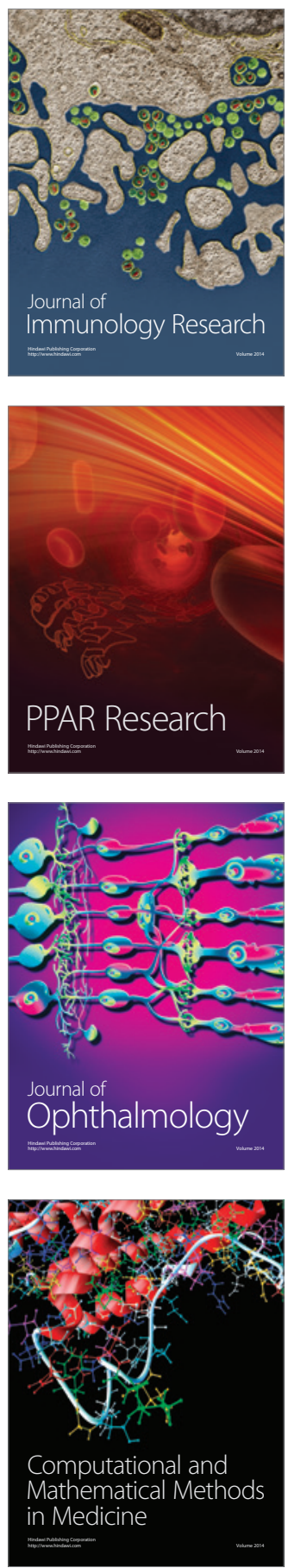

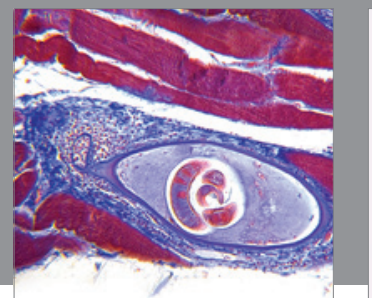

Gastroenterology

Research and Practice
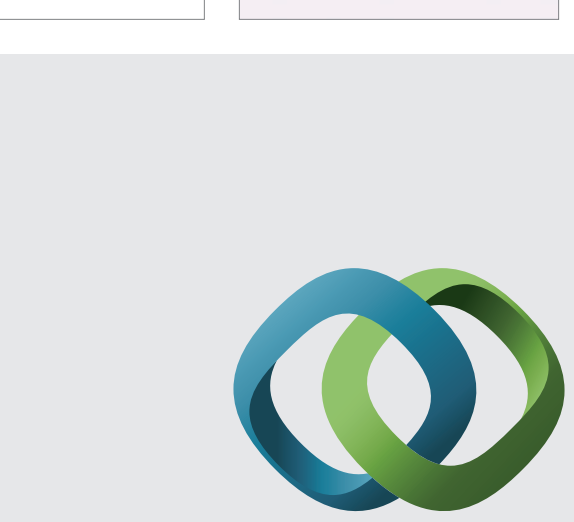

\section{Hindawi}

Submit your manuscripts at

http://www.hindawi.com
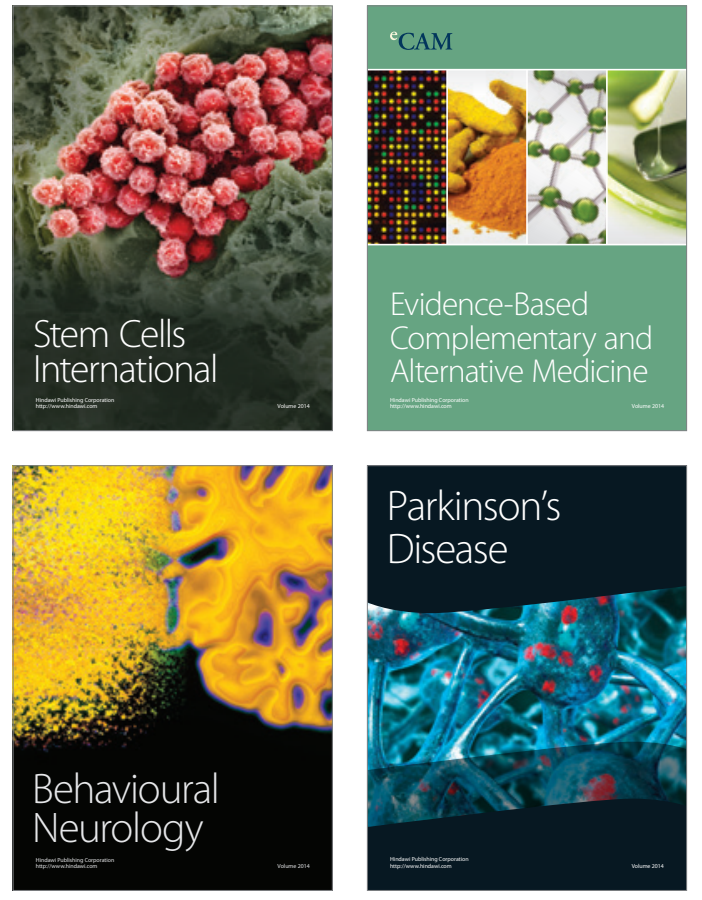
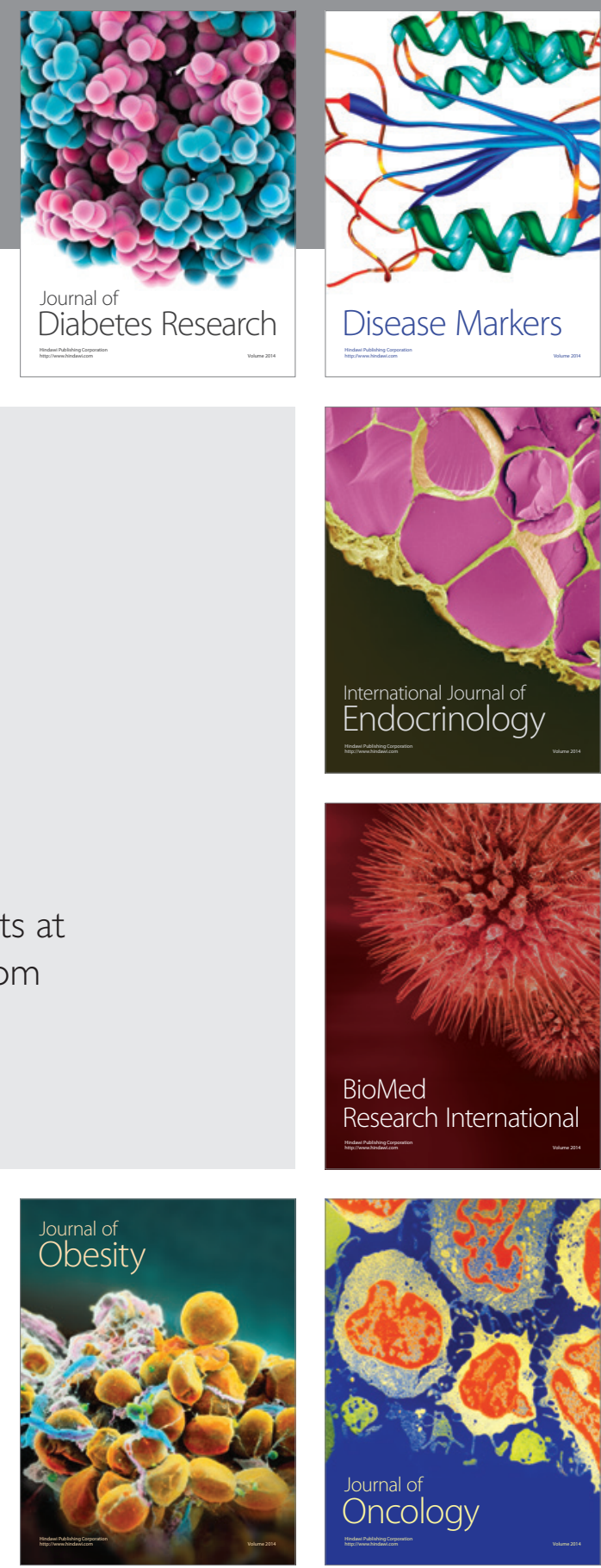

Disease Markers
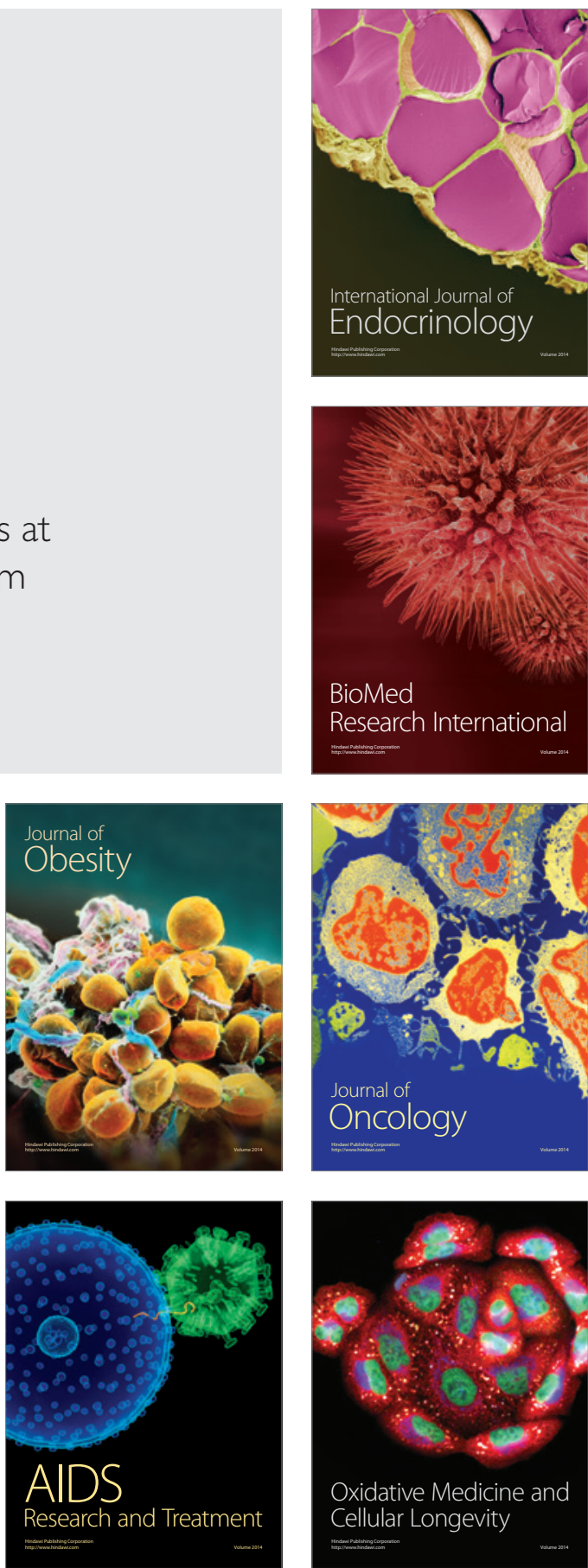